\title{
Pasienttilfredshet ved rehabilitering av pasienter med multippel sklerose
}

\author{
Engelsk oversettelse på www.tidsskriftet.no
}

\begin{abstract}
Sammendrag
Bakgrunn. Ved multippel sklerose fører motoriske og non-motoriske symptomer ofte til betydelig redusert helserelatert livskvalitet. Vi har undersøkt pasienttilfredshet og egenevaluering av nytten ved et spesialisert rehabiliteringsopphold.
\end{abstract}

Materiale og metode. Alle pasienter som var innlagt til rehabiliteringsopphold ved MS-Senteret Hakadal i 2010 ble bedt om å fylle ut et validert spørreskjema, beregnet på å kartlegge pasienttilfredshet ved rehabiliteringsinstitusjoner.

Resultater. Av totalt 339 pasienter leverte 277 (82\%) spørreskjemaet. De aller fleste respondentene var tilfredse med behandlernes kunnskaper, samarbeid, omsorg og engasjement, samt med forhåndsinformasjon og lokaliteter. De opplevde også å bli tatt med på råd vedrørende rehabiliteringsprogrammet, og å bli forberedt på tiden etter oppholdet. Mer enn $85 \%$ av respondentene oppga høyest eller nest høyest skår for oppholdets antatte betydning for generell livskvalitet og fysisk helse. Tilsvarende skår for psykisk helse var angitt av $83 \%$, mestring av daglige gjøremål av $74 \%$, og deltagelse i sosiale aktiviteter av $71 \%$.

Fortolkning. Pasientene som har deltatt på rehabiliteringsopphold ved MS-Senteret Hakadal er tilfredse, og tror oppholdet vil få stor betydning for deres funksjonsnivå og mestring.

Appendiks på

www.tidsskriftet.no/holmoyappendiks

> Se også side 506

\section{Trygve Holmøy}

trygve.holmoy@medisin.uio.no

Nevroklinikken

Akershus universitetssykehus

og

Institutt for klinisk medisin

Universitetet i Oslo

Kjersti Træland Hanssen

Nevroklinikken

Akershus universitetssykehus og

MS-Senteret Hakadal

Antonie G. Beiske

MS-Senteret Hakadal

Drøyt 7000 personer i Norge har multippel sklerose (MS) (1), som er den hyppigste sykdomsårsaken til nevrologisk invaliditet hos unge voksne. Sykdommen rammer kvinner om lag dobbelt så hyppig som menn, og debuterer oftest i aldersgruppen 20-40 år. Til tross for terapeutiske fremskritt utvikler de fleste pasientene symptomer som i betydelig grad reduserer deres helserelaterte livskvalitet (2). Foruten motoriske symptomer med bevegelsesinnskrenkning, spastisitet og koordinasjonssvikt, forekommer vannlatingsplager (urgeinkontinens og urinretensjon), avføringsplager (obstipasjon og fekal inkontinens), seksuell dysfunksjon, nevralgiske smerter, depresjon og utmattelse (fatigue) hyppig (3). Inntil $70 \%$ utvikler kognitive symptomer, hyppigst i form av vansker med hukommelse, kompleks oppmerksomhet, prosesseringshastighet og eksekutive funksjoner $(4,5)$.

MS-Senteret Hakadal er et landsdekkende rehabiliteringssenter dedikert for personer med multippel sklerose. Senteret tilbyr rehabiliteringsopphold av tre til fire ukers varighet, samt kortere informasjonskurs for nydiagnostiserte pasienter og kommunikasjonskurs for par. For å fremme gruppedynamikk og mulighet for likemannsarbeid, er tidspunkt for ankomst og avreise likt for deltakerne på samme opphold. Pasientene følges opp av et tverrfaglig team bestående av nevrolog, fysioterapeut, pleiepersonell, ergoterapeut og sosionom. Alle pasienter har i løpet av oppholdet minst to individuelle konsultasjoner hos nevrolog, og følges opp av fysioterapeut med et individuelt tilpasset treningsprogram. Det er daglig tilbud om gruppetrening og undervisning om ulike sykdomsrelaterte temaer, og mulighet for nevropsykologisk undersøkelse, psykologsamtaler, individuell kostveiledning, akupunktur og gruppesamtaler. Behov for kontakt med psykolog, nevropsykolog og kostveileder varierer mellom pasienter, og tilbudet om kontakt med disse yrkesgruppene er mer begrenset. Det tilstrebes en åpen, løsningsorientert dialog mellom pasienten og det tverrfaglige teamet, der resultater fra den tverrfaglige utredningen drøftes med pasienten $i$ lys av hans eller hennes livssituasjon, ønsker og behov. Individuelle mål og tiltak defineres ved starten av rehabiliteringsoppholdet, og måloppnåelse evalueres før hjemreise. Eksempler på individuelt tilpassete rehabiliteringsforløp er rehabilitering med arbeidsrettet fokus og rehabilitering med kognitivt fokus.

Det er begrenset kunnskap om hvilken effekt ulike rehabiliteringstiltak har. En relativt nylig litteraturgjennomgang konkluderte likevel med at det var «sterk evidens» for at opphold i tverrfaglig rehabiliteringsinstitusjon hadde positiv effekt på aktivitetsnivå og mestring (6). Det har tidligere blitt vist at fysikalsk behandling ved MS-Senteret fører til bedret motorisk funksjon (7). Formålet med denne studien var å kartlegge pasienttilfredshet og egenopplevd utbytte av et spesialisert rehabiliteringsopphold ved MSSenteret Hakadal.

\section{Materiale og metode}

Alle pasienter som var innlagt til rehabiliteringsopphold i 2010 ble bedt om å fylle ut et anonymisert evalueringsskjema ved oppholdets avslutning (appendiks). Evalueringsskjemaet er utarbeidet av Kunnskapssenteret for helsetjenesten på oppdrag fra De spesielle helseinstitusjoner, og er beregnet på å måle pasientenes erfaringer med opptreningsinstitusjoner, helsesportsentre og attføringsinstitusjoner (8). Skjemaet har faste svaralternativer for hvert enkelt spørsmål, og det er i tillegg mulighet for utfyllende kommentarer for de fleste av spørsmålene. Skjemaets reliabilitet og validitet er blitt vurdert som tilfredsstillende i en pilotunder-

\section{Hovedbudskap}

- Pasienter innlagt til rehabiliteringsopphold ved MS-Senteret Hakadal var stort sett tilfreds med organiseringen av tilbudet og oppfølgingen fra behandlerne

- De fleste mente oppholdet ville ha betydning for deres livskvalitet, psykiske og fysiske helse og mestring i dagliglivet 


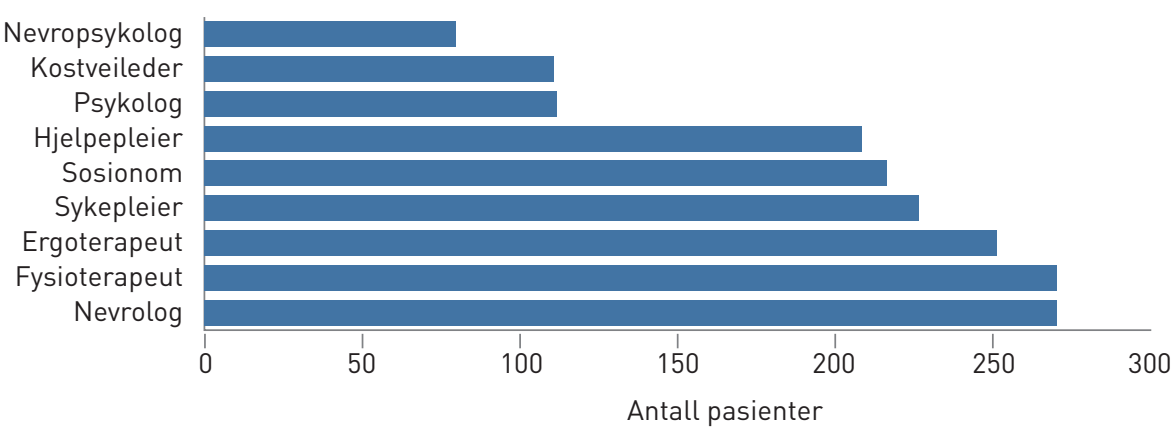

Figur 1 Pasientenes angivelse av kontakt med faggruppene ved MS-Senteret

søkelse som omfattet 371 pasienter ved åtte ulike rehabiliteringsinstitusjoner (8). Siden MS-Senteret Hakadal har tilknyttet psykolog og nevropsykolog, ble det i tillegg spurt direkte om kontakt med disse faggruppene. Pasientene ble informert om at utfyllingen var frivillig, og at dataene ville bli brukt $\mathrm{i}$ Senterets kvalitetssikring. I henhold til helseforskningsloven ble studien vurdert som et ledd i MS-Senterets kvalitetssikring og ikke som et forskningsprosjekt, og det ble derfor ikke søkt om godkjenning fra regional forskningsetisk komité. Manglende svar på enkeltspørsmål ble ikke etterlyst.

\section{Resultater}

Totalt 339 (217 kvinner, 122 menn) pasienter med gjennomsnittsalder 54 år gjennomførte et fire ukers rehabiliteringsopphold i løpet av studieperioden. Av disse leverte 277 (171 kvinner, 91 menn, 15 ikke oppgitt kjønn) evalueringsskjemaet. Den totale svarprosenten var således 82 .

Rapportert fordeling av kontakt med de ulike yrkesgrupper er angitt $i$ figur 1 .

Pasientenes vurdering av forhåndsinformasjon, organisering, mulighet for å påvirke oppholdet samt oppfølging fra behandlere er angitt i tabell 1. Andelen respondenter som var tilfredse var 77-97 \% for de ulike aspektene. Når pasientene som uttrykte misnøye vedrørende behandlerne kom med utfyllende kommentarer, var disse oftest knyttet til opplevelsen av manglende kompetanse og engasjement hos legen. Totalt fem pasienter uttrykte misnøye med senterets lege. Misnøye med diskontinuitet blant fysioterapeutene ble angitt av tre pasienter som hadde deltatt på et opphold der det hadde vært uvanlig fravær blant denne yrkesgruppen. Utover dette var det ingen gjennomgående momenter i de kritiske kommentarene. Enkelte syntes at oppholdet var for langvarig og andre at det var for kort, og noen at det var for mye program, mens andre syntes det var for lite program. Enkelte pasienter påpekte manglende forhåndsinformasjon om bassengtilbud, at det var begrenset kapasitet for rehabilitering med kognitivt fokus, og at det ikke var blitt kommunisert tydelig nok at senteret har egne kurs for par.

Pasientenes vurdering av rehabiliteringsoppholdets betydning for livskvalitet, psykisk- og fysisk helse, mestring og deltagelse i dagliglivet er angitt i tabell 2. Mer enn $85 \%$ av respondentene ga høyest eller nest høyest skår vedrørende oppholdets betydning for generell livskvalitet og fysisk helse. Tilsvarende skår for psykisk helse var angitt av $83 \%$, mestring av daglige gjøremål av $74 \%$, og deltakelse i sosiale aktiviteter av $71 \%$.

\section{Diskusjon}

Denne undersøkelsen viser at de fleste som har gjennomgått et fire ukers spesialisert rehabiliteringsopphold ved MS-Senteret Hakadal er tilfredse med oppholdet, og at de tror dette vil ha positiv innvirkning på deres generelle livskvalitet, fysiske og psykiske helse, mestring av daglige gjøremål og deltakelse i sosiale aktiviteter.

Såkalt pasientsentrerte effektmål tillegges økende betydning som kvalitetsindikator i helsetjenesten (9), også i behandling av multippel sklerose (10). Pasienttilfredshet er imidlertid avhengig både av pasientenes forventninger, prosesser i møtet mellom pasient og behandler, strukturelle og organisatoriske forhold ved helseinstitusjonen, samt pasientenes opplevelse av resultatet av behandlingen. Det er blitt hevdet at pasienter oftest mangler forutsetninger for å bedømme den faglige standarden på diagnostikk og behandling, og at de derfor i større grad vektlegger opplevelse av omsorg, medvirkning, lokaler og mat (11). Det er også blitt påpekt at høy pasienttilfredshet ikke nødvendigvis gjenspeiler høy faglig standard, blant annet fordi pasienter kan stille urimelige krav som det vil være mer eller mindre galt eller endog direkte skadelig å etterkomme (12). Dessverre mangler vi kunnskap om hvorvidt pasienttilfredshet er korrelert med andre mål på behandlingseffekt, slik som fysisk funksjonsevne, hjelpebehov og yrkesdeltakelse etter utskrivning. Vi vet heller ikke hvor vedvarende tilfredshet ved utskri-

Tabell 1 Tilfredshet med ulike aspekter ved rehabiliteringsoppholdet. Antall manglende svar blant respondentene var 7-35 på de ulike spørsmålene

$\begin{array}{cc}\text { Ja } & \text { Nei } \\ \text { Antall (\%) } & \text { Antall (\%) } \\ 224(81) & 27(10) \\ 213(77) & 32(12) \\ 255(92) & 14(5) \\ 268(97) & 2(1) \\ 266(96) & 4(1) \\ 262(95) & 5(2) \\ 238(86) & 8(3) \\ 229(83) & 13(5) \\ 242(87) & 4(1) \\ 224(81) & 24(9) \\ 248(90) & 21(8) \\ 260(94) & 9(3) \\ 256(92) & 10(4) \\ 249(90) & 5(2)\end{array}$


Tabell 2 Pasientenes egenvurdering av nytten av rehabiliteringsoppholdet $11=i$ liten grad, 4 = i stor grad). Antall manglende svar blant respondentene var 11-24 på de ulike spørsmålene

Hvilket utbytte tror du at opphold
Livskvalitet generelt?
Fysiske helse?
Psykiske helse?
Mestring av daglige gjøremål?
Deltakelse i sosiale aktiviteter?

ving er over tid. Et ensidig fokus på pasienttilfredshet ved endt opphold kan derfor tenkes å være en dårlig rettesnor for prioriteringer $\mathrm{i}$ helsetjenesten (13). På den annen side er det langt fra åpenbart at behandlerdefinerte effektmål gir et sannere eller mer relevant bilde av kvaliteten på rehabiliteringstilbudet ved kroniske og alvorlige sykdommer som multippel sklerose, der mer objektive mål som yrkesdeltakelse og uavhengighet av helse- og omsorgstjenesten ofte er utopisk. Det er også tankevekkende at bedring av fysisk funksjonsnivå, som er relativt enkelt å kvantitere med objektive tester, ikke nødvendigvis korrelerer med helserelatert livskvalitet (7). Pasienttilfredshet representerer derfor en egenverdi som er uavhengig av behandlerdefinerte effektmål.

Flertallet av MS-Senterets pasienter har relativt god kjennskap til senteret på forhånd, blant annet gjennom tidligere innleggelser. Dette vil kunne medføre en seleksjon av pasienter som er tilfredse med den behandlingsformen som tilbys, slik at høy grad av pasienttilfredshet kan fremstå som en selvoppfyllende profeti. Det er derfor viktig at behovet og forventningene til rehabilitering kartlegges også hos pasienter som ikke søker seg til eksisterende rehabiliteringstilbud.

Selv om kognitive symptomer er hyppige ved multippel sklerose, mangler vi kunnskap om hvilke tiltak som er hensiktsmessige $(14,15)$. MS-senteret har utviklet en modell for kognitiv rehabilitering, og noen deltakere i studien som presenteres i denne artikkelen, deltar også i en prospektiv evaluering av denne modellen. Modellen omfatter nevropsykologisk undersøkelse, ukentlige individualsamtaler med nevropsykolog og ergoterapeut, samt gruppebasert undervisning, praktiske øvelser og erfaringsutveksling. Deltakerne får veiledning i å sette opp mål for mestring av kognitive utfordringer i hverdagen, og etter rehabiliteringsoppholdet følges de opp med telefonsamtaler med fokus på måloppnåelse. Kun om lag en tredel av pasientene $\mathrm{i}$ vår studie rapporterte at de hadde vært i kontakt med psykolog eller nevropsykolog. Dette gjenspeiler delvis at tilgangen på disse faggruppene er begrenset, noe som understøttes av tilbakemeldinger fra enkelte pasienter som var misfornøyd med at de ikke fikk innfridd sitt ønske om kognitiv rehabilitering. Heller ikke alle pasienter rapporterte at de hadde vært i kontakt med lege eller fysioterapeut, selv om alle pasienter har individuelle konsultasjoner med disse yrkesgruppene. Det er mulig at dette gjenspeiler at enkelte pasienter var misfornøyd med kontakten med disse yrkesgruppene. Denne muligheten støttes imidlertid ikke av korresponderende fritekstkommentarer fra dem som ikke oppga å ha vært i kontakt med lege eller fysioterapeut.

Styrken ved denne studien er høy deltakelse og høy svarprosent på hvert enkelt spørsmål, samt anvendelsen av et validert spørreskjema. Vi kan derfor anta at resultatene er representative for pasientene som var innlagt ved MS-Senteret i studieperioden. Studien har imidlertid også flere begrensninger. Mange av spørsmålene var såvidt generelle at svarene $i$ liten grad er egnet til å identifisere sider av rehabiliteringsoppholdet som eventuelt bør endres. Ettersom de aller fleste pasienter var svært fornøyd med oppholdet, er det ikke tilstrekkelig spredning i dataene til å utføre statistisk analyse med tanke på korrelasjon mellom svarene på de ulike spørsmålene. Videre mangler longitudinelle data, som kunne gjort det mulig å undersøke om endringer i driften har hatt innvirkning på pasienttilfredsheten. En annen begrensning er at faktorer som alder, kjønn og grad av funksjonshemning hos den enkelte respondent ikke ble kartlagt, og vi kan derfor ikke trekke lærdom i forhold til om tilbudet bør justeres i forhold til enkelte pasientgrupper (16). Betydningen av dette er imidlertid sannsynligvis begrenset, ettersom de aller fleste pasienter er fornøyde. Vi har heller ikke undersøkt andre effektmål, og kan derfor ikke trekke slutninger om pasienttilfredshet korrelerer med bedret funksjonsevne, helserelatert livskvalitet eller andre relevante mål for effekt av rehabiliteringsoppholdet.

Vi takker Chris Aasgaard og Oddbjørg Gangås for systematisering av data fra spørreskjemaer.

er overlege ved Nevroklinikken, Akershus universitetssykehus og professor ved Institutt for klinisk medisin, Universitetet i Oslo. Han har multippel sklerose som sitt viktigste forskningsfelt.

Forfatter har fylt ut ICMJE-skjemaet og oppgir ingen interessekonflikter.

\section{Trygve Holmøy (f. 1960)}

\section{Kjersti Træland Hanssen (f. 1973)}

er spesialist i klinisk nevropsykologi. Hun er ansatt ved Nevroklinikken, Akershus universitetssykehus og MS-Senteret Hakadal. Forfatter har fylt ut ICMJE-skjemaet og oppgir ingen interessekonflikter.

\section{Antonie Giæver Beiske (f. 1949)}

er daglig leder ved MS-Senteret Hakadal. Hun er nevrolog ph.d. vedrørende rehabilitering ved multippel sklerose.

Forfatter har fylt ut ICMJE-skjemaet og oppgir følgende interessekonflikter: Har mottatt forelesningshonorar fra Novartis og reisestøtte til kongressdeltakelse fra Merck Serono og Biogen.

\section{Litteratur}

1. Risberg G, Aarseth JH, Nyland $\mathrm{H}$ et al. Prevalence and incidence of multiple sclerosis in Oppland County - a cross-sectional population-based study in a landlocked county of Eastern Norway. Acta Neurol Scand 2011; 124: $250-7$

2. Beiske AG, Naess H, Aarseth JH et al. Health-related quality of life in secondary progressive multiple sclerosis. Mult Scler 2007: 13: 386-92.

3. Thompson AJ, Toosy AT, Ciccarelli O. Pharmacolo gical management of symptoms in multiple scler osis: current approaches and future directions. Lancet Neurol 2010: 9: 1182-99.

4. O'Brien AR, Chiaravalloti N, Goverover Y et al. Evidenced-based cognitive rehabilitation for persons with multiple sclerosis: a review of the literature. Arch Phys Med Rehabil 2008; 89 : $761-9$.

5. Amato MP, Ponziani G, Siracusa $G$ et al. Cognitive dysfunction in early-onset multiple sclerosis: a reappraisal after 10 years. Arch Neurol 2001; 58: $1602-6$

6. Khan F, Turner-Stokes L, Ng L et al. Multidisciplinary rehabilitation for adults with multiple sclerosis. Cochrane Database Syst Rev 2007; nr. 2: CD006036

7. Smedal T, Myhr KM, Aarseth JH et al. The influence of warm versus cold climate on the effect of physiotherapy in multiple sclerosis. Acta Neurol Scand 2011; 124: 45-52.

8. Holmboe 0, Sjetne IS, Garratt A et al. Utvikling av metode for måling av pasienters erfaringer med private rehabiliteringsinstitusjoner. PasOpp-rapport nr $01-2009$. Oslo: Nasjonalt kunnskapssenter for helsetjenesten, 2009

9. Roland M, Rosen R. English NHS embarks on controversial and risky market-style reforms in health care. N Engl J Med 2011; 364: 1360-6.

10. Miller D, Rudick RA, Hutchinson M. Patient-centered outcomes: translating clinical efficacy into benefits on health-related quality of life. Neurology 2010; 74 (suppl 3): S24-35.

11. Sitzia J, Wood N. Patient satisfaction: a review of issues and concepts. Soc Sci Med 1997; 45: 1829-43.

12. Frich JC, Ramleth O. Pasienttilfredshet som mål for kvalitet i spesialisthelsetjenesten. Tidsskr Nor Lægeforen 2004; 124: 88.

13. Chassin MR, Loeb JM, Schmaltz SP et al. Accountability measures-using measurement to promote quality improvement. N Engl J Med 2010; 363 : 683-8

14. O'Brien AR, Chiaravalloti N, Goverover Y et al. Evidenced-based cognitive rehabilitation for persons with multiple sclerosis: a review of the literature. Arch Phys Med Rehabil 2008; 89 $761-9$.

15. Thomas PW, Thomas S, Hillier $C$ et al. Psychologi cal interventions for multiple sclerosis. Cochrane Database Syst Rev 2006: nr. 1: CD004431.

16. Foss C, Hofoss D. Patients' voices on satisfaction unheeded women and maltreated men? Scand J Caring Sci 2004; 18: 273-80. 